\title{
Atypical, Multilevel, and Noncontiguous Tuberculous Spondylitis Affecting the Cervical, Thoracic, Lumbar, and Sacral Vertebrae, Clivus, and Manubrium Sterni in a Pulmonary Tuberculosis Patient
}

\author{
Hanuman Prasad Prajapati ${ }^{1}$ Devendra Purohit ${ }^{1}$ \\ ${ }^{1}$ Department of Neurosurgery, SMS Medical College and Hospital, \\ Jaipur, Rajasthan, India
}

Indian J Neurosurg 2021;10:260-262.

Tubercular spondylitis is a common extrapulmonary manifestation of tuberculosis. It accounts for $50 \%$ of skeletal tuberculosis. ${ }^{1}$ In most cases, associated symptoms are not so unique as to immediately indicate the proper diagnosis. Differentiating spinal tuberculosis from pyogenic osteomyelitis is often very difficult, and metastatic lesion from systemic malignancy is the other major entity from which spinal tuberculosis must be differentiated. Noncontiguous multilevel involvement of tubercular spondylitis is relatively rare, and most of the reported cases had lesion only at two levels. ${ }^{2-5}$ Very few cases with extreme bony involvement have been reported in the published literature.

An 18-year-old female patient presented with 1-year history of low back pain, occasional mild fever associated with night sweat, and decreased weight and appetite. There was visible kyphotic deformity at mid back region, and tenderness was present over low back region. There was no history of trauma, cough, hemoptysis, cervical and upper back pain, and bladder bowel involvement.

On physical examination, tone was normal in both upper and lower limbs, and power was also normal at all joints in both upper and lower limbs, except bilateral extensor hallucis longus (EHL) weakness. Her reflexes were ++ in bilateral upper and lower limbs, and tenderness was present over lower back region on palpation. Kyphotic deformity was present over mid back region. Routine blood examination was normal. Erythrocyte sedimentation rate (ESR) was $61 \mathrm{~mm} / 1 \mathrm{st}$ hour, and C-reactive protein was positive. Her metastatic profile, tumor markers, and viral markers were negative.

Computed tomography (CT) of the spine shows multilevel, noncontiguous osteolytic lesion with perilesional sclerosis at the time of admission. They are found at C2, C4, D3, D9,

published online September 28, 2021
DOI https://doi.org/

$10.1055 / \mathrm{s}-0039-1677964$ ISSN 2277-954X.
Address for correspondence Hanuman Prasad Prajapati, MCh, Department of Neurosurgery, SMS Medical College and Hospital, Jaipur 302004, Rajasthan, India (e-mail: pushpa84.dhp@gmail.com).

D11, L1, L3, L5, and S2 vertebral body along with involvement of clivus and manubrium sterni (-Fig. 1). There was also involvement of posterior element of D7-D11 vertebra ( - Fig. 2A). There was also evidence of pulmonary tuberculosis on CT of the chest. Magnetic resonance imaging (MRI) shows hypointense signal on T1WI and hyperintense signal on T2WI at L5 vertebral body level along with epidural pus collection causing compression over thecal sac ( - Fig. 2B). Fine-needle aspiration cytology (FNAC) was done from L5 vertebral body level, which was suggestive of tubercular granulation tissue.

The patient was planned for surgery to establish the tissue diagnosis and also for decompression of thecal sac. L5 laminectomy with suction evacuation of anterior epidural abscess with decompression of thecal sac was done. Histopathologic examination of tissue obtained from surgery was suggestive of inflammatory granulation tissue composed of lymphoplasmacytic cells and some epithelioid cells. Acid-fast bacillus (AFB) examination from sample obtained from the patient's sputum was also positive for mycobacterium tuberculosis. Postoperative period was uneventful, and the patient was discharged on 12th day on antitubercular drugs.

Extrapulmonary tuberculosis consists of 15 to $20 \%$ of patients with tuberculosis, out of which skeletal tuberculosis is $10 \%$, and out of these patients, tubercular spondylitis accounts for approximately $50 \% .^{6}$ Numerous literature indicate that approximately $90 \%$ patients with tubercular spondylitis had only one spinal lesion. In contrast only a small percentage of patients with tubercular spondylitis had two to three spinal lesions, and patients having more than three spinal lesions are rarely found. The underlying reason for the rarity of multilevel, noncontiguous tubercular spondylitis is currently unknown, even though it is thought that tuberculosis of the spine spreads through hematogenous route.

(C) 2021. Neurological Surgeons' Society of India.

This is an open access article published by Thieme under the terms of the Creative Commons Attribution-NonDerivative-NonCommercial-License, permitting copying and reproduction so long as the original work is given appropriate credit. Contents may not be used for commercial purposes, or adapted, remixed, transformed or built upon. (https://creativecommons.org/licenses/by-nc-nd/4.0/).

Thieme Medical and Scientific Publishers Pvt. Ltd. A-12, 2nd Floor, Sector 2, Noida-201301 UP, India 

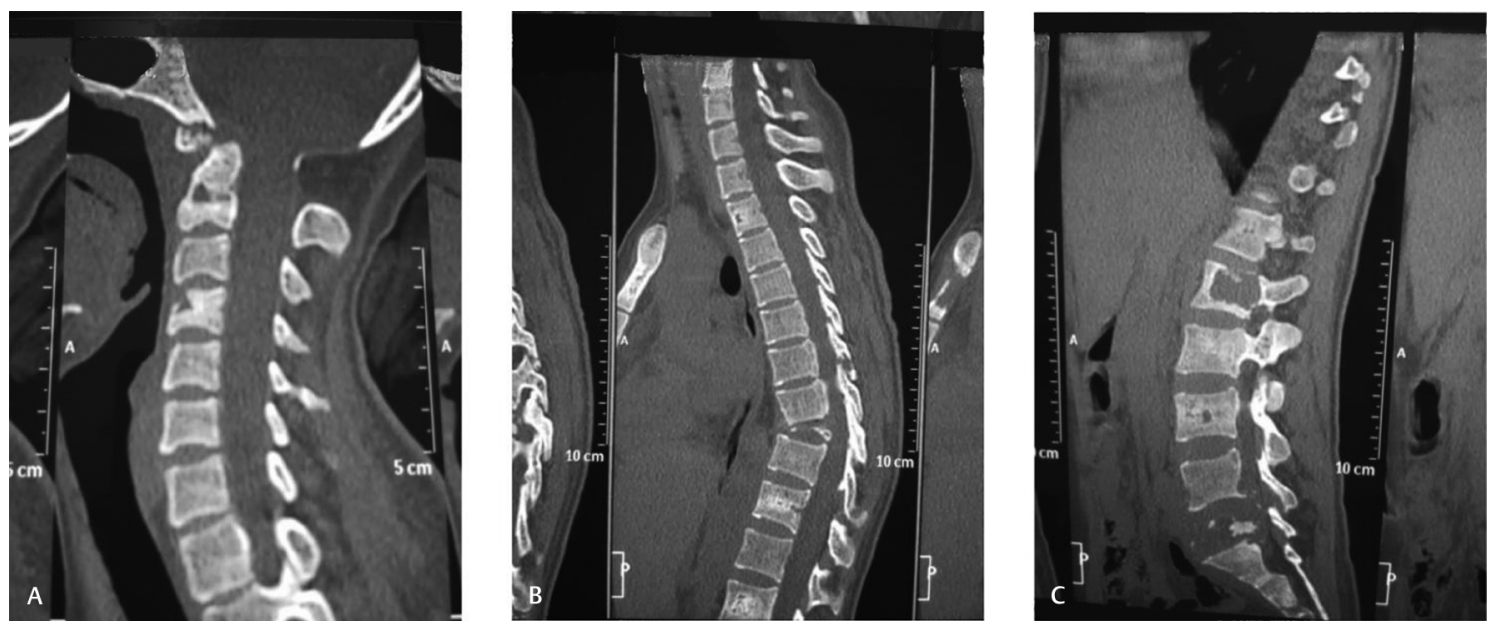

Fig. 1 (A-C) Plain CT saggital section of the spine suggestive of involvement of clivus, C2, C4, D3, D9, D11, L1, L3, L5, and S2 vertebral body along with involvement of manubrium sterni.
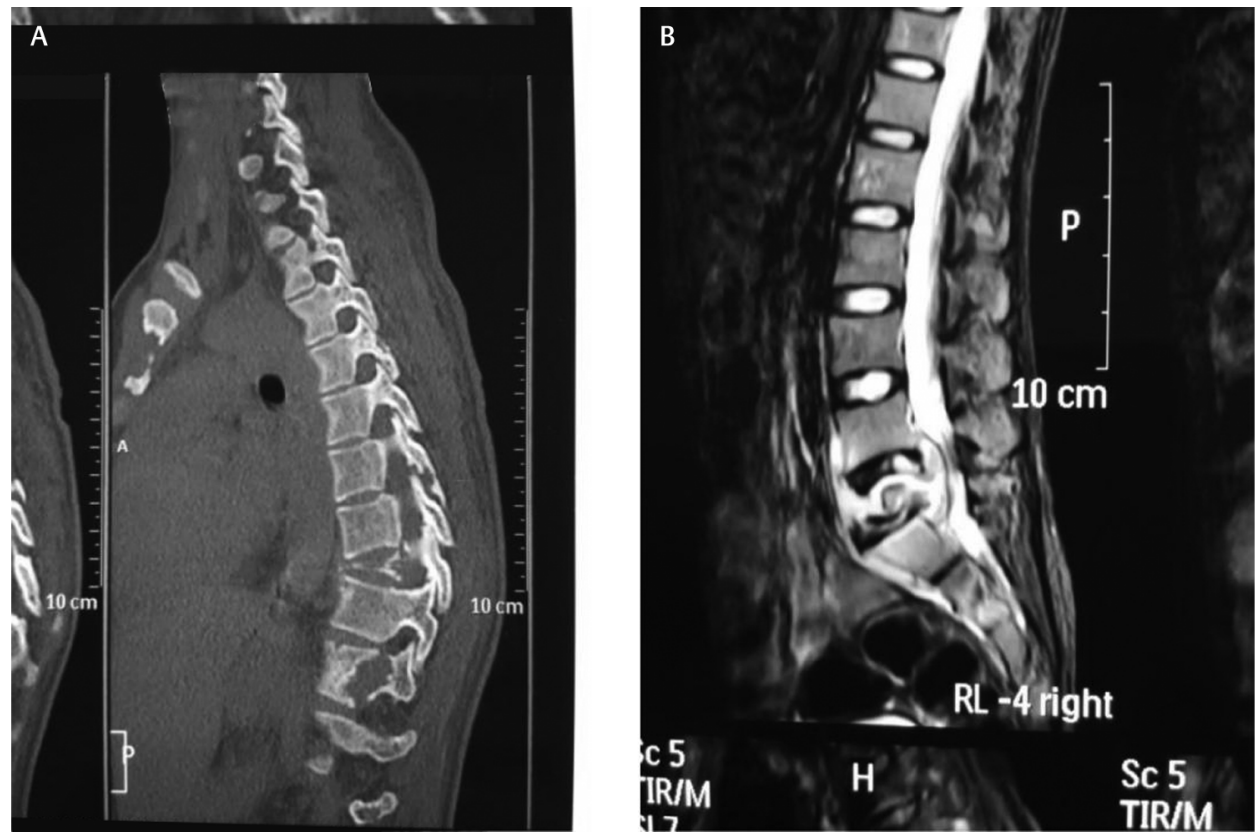

Fig. 2 (A) Plain CT saggital section of the spine suggestive of involvement of posterior element of D7-D11 vertebra. (B) T2W MRI saggital section of lumbosacral spine suggestive of collapse of $L 5$ vertebral body along with paravertebral collection of pus.

Multiple metastatic spinal lesions from systemic malignancy are the major entity from which multilevel spinal tuberculosis must be differentiated. Metastasis characteristically spares the disc space that is primarily involved in spinal tuberculosis. When the spinal tuberculosis involves the multiple noncontiguous vertebrae, its imaging appearance can be easily mistaken for metastatic malignancy. Factors that indicate and differentiate spinal tuberculosis from neoplastic disease include the presence of paravertebral abscess and subligamentous spread. In our case tuberculosis involves mainly the vertebral body, not the pedicle that impressed spinal tuberculosis rather than other malignancy.

Atypical spinal tuberculosis shares several features in common as reported by Naim-Ur-Rahman et al. ${ }^{7,8}$ First, atypical tuberculous lesions readily involve the neural arch, sparing the vertebral body and disc (referred to as posterior potts). Second, skip lesions are also present, as defined by the presence of two or more vertebral lesions separated by the uninvolved vertebrae. Finally, lesion may manifest as solid tumorlike mass with no evidence of abscess formation, discovered at the time of surgery and indistinguishable from a solid spinal extradural tumor.

In this case, imaging study revealed osteolytic lesion involving the cervical, thoracic, lumbar, and sacral vertebrae along with the manubrium sterni and clivus. Perilesional sclerosis indicates chronicity of infection. Skip lesion was also found. In the cervical, thoracic, and upper lumbar region, there was no evidence of abscess formation. There was involvement of posterior element. Therefore, all 
these features meet the atypical criteria for tuberculous spondylitis as described by Naim-Ur-Rahman. Abscess formation was present at L5 vertebral body level, which shows the typical form of spinal tuberculosis. Histologic confirmation was also supportive of diagnosis. Features also in favor of spinal tuberculosis include the simultaneous presence of pulmonary tuberculosis and absence of any systemic malignancy in the chest, abdomen, and pelvic viscera, which favors secondary lesion to the spine.

Tuberculosis of the spine may present in its atypical form. Metastatic lesion, tubercular spondylitis, and pyogenic spondylitis must be considered in the differential diagnosis of multiple spinal lesions. CT and MRI of the spine are the major tool to differentiate these lesions, but histopathologic confirmation should be done in every cases.

\section{Funding}

None.

\section{Conflict of Interest}

None declared.

\section{References}

1 Ansari S, Amanullah MF, Ahmad K, Rauniyar RK. Pott's spine: diagnostic imaging modalities and technology advancements. N Am J Med Sci 2013;5(7):404-411
2 Kulali A, Cobanoğlu S, Ozyilmaz F. Spinal tuberculosis with circumferential involvement of two noncontiguous isolated vertebral levels: case report. Neurosurgery 1994;35 (6): $1154-1158$

3 Janssens JP, de Haller R. Spinal tuberculosis in a developed country. A review of 26 cases with special emphasis on abscesses and neurologic complications. Clin Orthop Relat Res 1990;257(257):67-75

4 Turgut M. Multifocal extensive spinal tuberculosis (Pott's disease) involving cervical, thoracic and lumbar vertebrae. Br J Neurosurg 2001;15(2):142-146

5 Emel E, Güzey FK, Güzey D, Bas NS, Sel B, Alatas I. Non-contiguous multifocal spinal tuberculosis involving cervical, thoracic, lumbar and sacral segments: a case report. Eur Spine J 2006;15(6):1019-1024

6 Polley P, Dunn R. Noncontiguous spinal tuberculosis: incidence and management. Eur Spine J 2009;18(8): 1096-1101

7 Naim-UR-Rahman. Atypical forms of spinal tuberculosis. J Bone Joint Surg Br 1980;62-B(2):162-165

8 Naim-ur-Rahman, El-Bakry A, Jamjoom A, Jamjoom ZA, Kolawole TM. Atypical forms of spinal tuberculosis: case report and review of the literature. Surg Neurol 1999;51 (6):602-607 